\title{
Environmental soil contamination by Toxocara species eggs in public places of Ilam, Iran
}

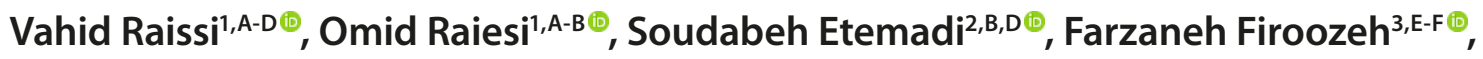 \\ Muhammad Getso ${ }^{1, D-E} \oplus$, Afkar Muslim Hadi ${ }^{4, D-E} \oplus$, Mohammad Zibaei ${ }^{5,6, A, D-F \oplus}$ \\ ${ }^{1}$ Department of Parasitology and Mycology, School of Public Health, Tehran University of Medical Sciences, Tehran, Iran \\ 2 Department of Medical Parasitology and Mycology, Faculty of Medicine, Zahedan University of Medical Sciences, \\ Zahedan, Iran \\ ${ }^{3}$ Department of Microbiology, School of Medicine, Alborz University of Medical Sciences, Karaj, Iran \\ ${ }^{4}$ Iraq Natural History Research Center and Museum, University of Baghdad, Baghdad, Iraq \\ ${ }^{5}$ Department of Parasitology and Mycology, School of Medicine, Alborz University of Medical Sciences, Karaj, Iran \\ ${ }^{6}$ Evidence- Based Phytotherapy and Complementary Medicine Research Center, Alborz University of Medical Sciences, \\ Karaj, Iran \\ A - Research concept and design, B - Collection and/or assembly of data, C - Data analysis and interpretation, \\ $D$ - Writing the article, E - Critical revision of the article, F - Final approval of article
}

Raissi V, Raiesi O, Etemadi S, Firoozeh F, Getso M, Hadi AM, Zibaei M. Environmental soil contamination by Toxocara species eggs in public places of Ilam, Iran. Ann Agric Environ Med. 2020; 27(1): 15-18. DOI: 10.26444/aaem/118130

\begin{abstract}
Introduction. The purpose of the study is to assess environmental contamination by Toxocara species eggs in public places in the city of Ilam, llam Province, southwest Iran

Materials and method. Between September 2018 and March 2019, 130 soil samples were collected from public places of 5 district municipalities of Ilam, southwest Iran. Soil samples were examined by microscopy following flotation method by sodium nitrate.

Results. Soil analysis showed that $5.88 \%$ of the soils stored, $52.54 \%$ from gardens, $29.42 \%$ from rubbish, and $11.72 \%$ from green spaces were contaminated with Toxocara spp. eggs. In total, $13.08 \%$ of soil samples (17/130) were positive for Toxocara eggs $(P>0.05)$.

Conclusions. The findings revealed that care should be taken when using soil from gardens, green spaces and rubbish, and also should be seriously considered because of the potential issues of toxocariasis and also the risk to the public.
\end{abstract}

\section{Key words}

Toxocara eggs, soil, contamination, public places, Iran

\section{INTRODUCTION}

Toxocariasis is a zoonotic disease caused mainly by Toxocara canis (T. canis) and Toxocara cati ( $T$. cati), intestinal nematodes of dogs and cats, respectively. Transmission to humans occurs by ingestion of embryonated Toxocara spp. eggs in the soil, water and vegetables, or through contaminated hands and fomites, and/or eating the meat of paratenic hosts containing encapsulated larvae [1-5]. Most infections do not have any clinical symptoms, athough Toxocara larvae are released within the different tissues and organs and may cause dangerous clinical syndromes, including weight loss, fever with a cough and shortness of breath, generalized lymphadenopathy and hepatomegaly [6-8]. The diagnosis of human toxocariasis is mainly based on clinical symptoms, epidemiological and laboratory data, which include imagining features, peripheral blood eosinophil, total IgE level, and serological findings using Enzyme-linked immunosorbentassay (ELISA) and Western blotting (WB) [9]. In big cities, the soils of the public places, such as green spaces, can become an important source of parasites contamination because domestic and stray dogs and cats have the highest mobility in these areas. In Iran, previous

Address for correspondence: Mohammad Zibaei, Alborz University of Medical Sciences, Iran

E-mail: zibaeim@sums.ac.ir

Received: 03.09.2019; Accepted: 02.02.2020; First published: 03.03.2020 studies have shown that the prevalence of Toxocara species eggs in soil samples from the public places varied from $2.3 \%$ in Qazvin to 63.3\% in Khorram Abad [4].

\section{OBJECTIVE}

Given the abundance of stray dogs and cats, and that toxocariasis could be a dangerous clinical complication in humans, the aim of the current research was to investigate the prevalence of Toxocara eggs in soils from the public places of 5 district municipalities in Ilam, southwest Iran.

\section{MATERIALS AND METHOD}

Study area. Ilam (33 38' $14^{\prime \prime} \mathrm{N}$ and $\left.4625^{\prime} 21^{\prime \prime} \mathrm{E}\right)$ is the capital of Ilam province, Iran (Fig. 1). The climate of the city is moderate and the temperatures vary between $-13.6-41.2^{\circ} \mathrm{C}$. The study was conducted between September 2018 and March 2019. The public places of 5 district municipalities in the city of Ilam were selected for sampling, regarding the size of the area and the mobility of the animals.

Samples collection. The study was performed on 130 soil samples collected in the public places of 5 municipality districts in the city of Ilam in order to recover Toxocara spp. eggs. A soil 


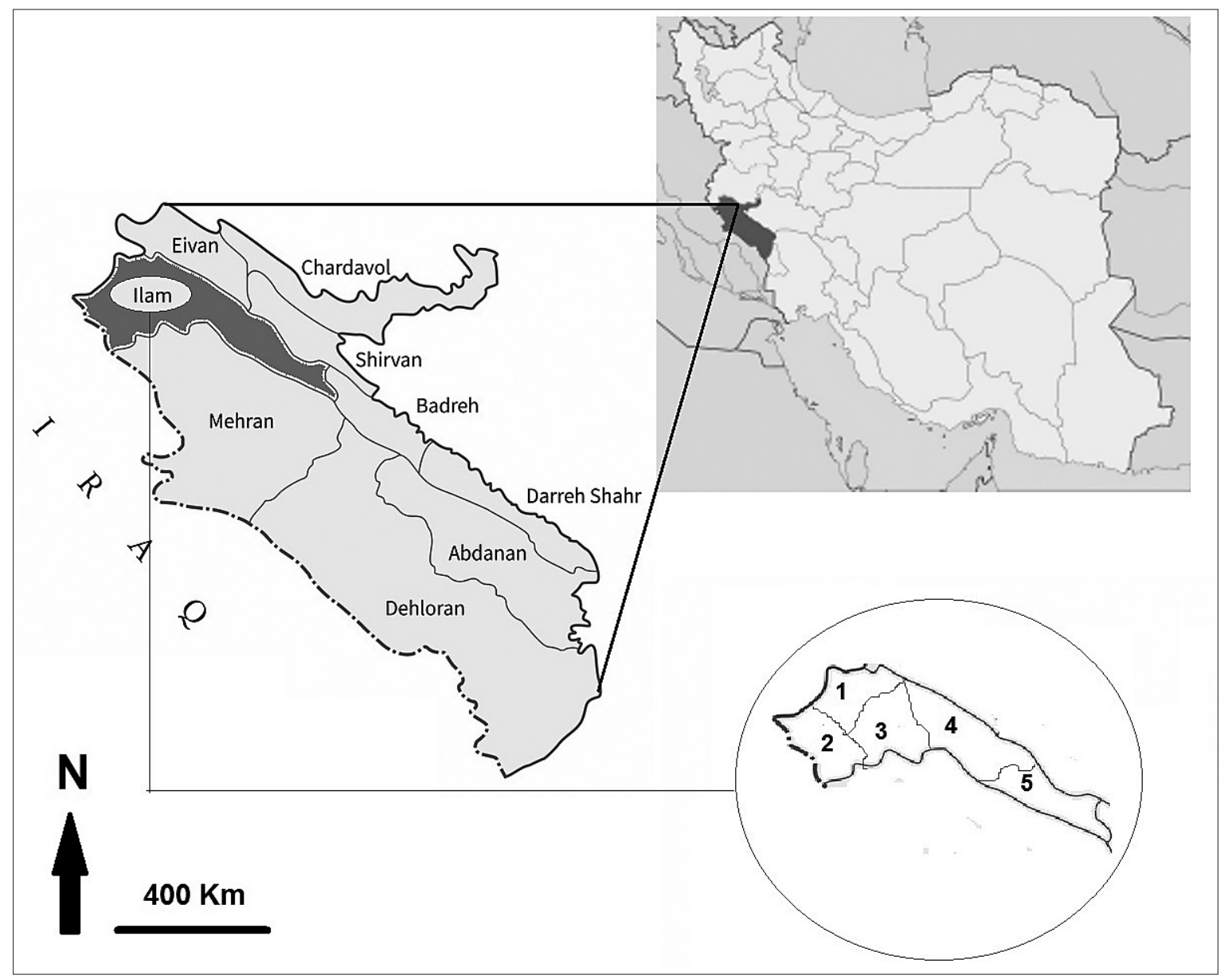

Figure 1. Regions in Ilam district from which soil samples were examined for Toxocara eggs

sample of 150-200 g per 4 sq m area was collected at a depth of $3 \mathrm{~cm}$. This resulted in 19-28 samples per specified area. The soil samples from the same site were thoroughly mixed and stored in sealed and labeled polythene bags, and taken to a laboratory for recovery of Toxocara eggs.

Detection of eggs. For eggs detection, soil samples were examined according to the method described by Zibaei et al. [2]. The tests were carried out in triplicate. Briefly, soil samples (dried at room temperature and sifted through a $150 \mu \mathrm{m}$ mesh sieve) were placed in flat-bottomed flasks and $5 \% \mathrm{NaOH}$ (Merck, Germany) was added to separate the eggs from the soil particles. The contents of the flasks were stirred and allowed to settle for $1 \mathrm{~h}$, before being shaken for $20 \mathrm{~min}$ at $100 \mathrm{rpm}$. After this vigorous mixing, they were placed in test tubes and centrifuged for $5 \mathrm{~min}$ at 1,500 rpm, following which the supernatants were removed from the test tubes and replaced with tap water.

The mixture was centrifuged again for $5 \mathrm{~min}$ at 1,500 rpm. After spinning, the $\mathrm{H}_{2} \mathrm{O}$ was discarded, a saturated $\mathrm{NaNO}_{3}$ solution was added to the pellet and centrifuged for $5 \mathrm{~min}$ at $1,500 \mathrm{rpm}$. The tubes were transferred to tripods and saturated $\mathrm{NaNO}_{3}$ solution was added with a pipette to form a convex meniscus. A coverslip was placed over each sample, and after $30 \mathrm{~min}$ they were placed on a microscope slide. The preparations were evaluated at magnifications of $x 400$ and x1,000 under a light microscope for the presence of Toxocara spp. eggs. Toxocara species eggs were identified only at the genus level due to remarkable morphological similarities.
Statistical analysis. All epidemiological and laboratory data was tested for their association with toxocariasis. Chi-square test and Fisher's exact test were used for categorical data. A $P$-value less than 0.05 was considered statistically significant.

\section{RESULTS}

Parasite eggs were found in $13.08 \%$ (17/130) of samples. Among the samples studied, the number of Toxocara eggs recovered varied from 1-9 with a mean of 4 eggs per $100 \mathrm{~g}$ of soil samples.

The relationship between the location and contamination of soil sample is shown in Table 1. There was no significant

Table 1. Recovery of eggs of Toxocara spp. from soil samples at each site

\begin{tabular}{|c|c|c|c|c|c|c|c|c|}
\hline \multirow[b]{3}{*}{ Soils } & \multicolumn{5}{|c|}{ Soil samples (No.*) } & \multirow{3}{*}{$\begin{array}{c}\text { Total } \\
\text { No. (\%) }\end{array}$} & \multirow{3}{*}{$\begin{array}{c}\text { Toxocara } \\
\text { spp. eggs } \\
\text { No. (\%) }\end{array}$} & \multirow[b]{3}{*}{ P-value } \\
\hline & \multicolumn{5}{|c|}{ Areas } & & & \\
\hline & 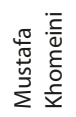 & $\begin{array}{l}\frac{\bar{c}}{\pi} \\
\frac{5}{5} \\
\frac{\pi}{\pi} \\
\vdash\end{array}$ & 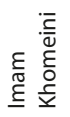 & 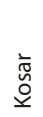 & $\begin{array}{l}\varepsilon \\
\mathbb{d} \\
\frac{\pi}{\cup} \\
\frac{5}{U}\end{array}$ & & & \\
\hline Garden & 10 & 12 & 18 & 7 & 3 & $50(38.46)$ & $9(52.94)$ & \\
\hline Stored & 6 & 1 & 5 & 2 & 1 & $15(11.54)$ & $1(5.88)$ & \\
\hline Green space & 5 & 4 & 10 & 2 & 2 & $23(17.70)$ & $2(11.76)$ & כנדי. \\
\hline Rubbish & 9 & 10 & 15 & 5 & 3 & $42(32.30)$ & $5(29.42)$ & \\
\hline
\end{tabular}

*Number

${ }^{\ddagger}$ No statistically significant difference in prevalence of the parasite among soil samples $(P>0.05)$ 
Table 2. Prevalence of Toxocara spp. eggs in soils of different areas in Ilam

\begin{tabular}{lcccc}
\hline Areas & $\begin{array}{c}\text { No.* } \\
\text { of Samples }\end{array}$ & $\begin{array}{c}\text { Toxocara spp. eggs } \\
\text { No. (\%) }\end{array}$ & $\begin{array}{c}\text { Prevalence } \\
\text { Ratio }\end{array}$ & P-value ${ }^{f}$ \\
\hline Mustafa Khomeini & 30 & $4(23.53)$ & 1 & 0.857 \\
\hline Talaghani & 27 & $3(17.65)$ & 0.9 & \\
\hline Imam Khomeini & 48 & $6(35.29)$ & 0.9 \\
\hline Kosar & 16 & $3(17.65)$ & 1.5 \\
\hline Ghaem & 9 & $1(5.88)$ & 0.8 \\
\hline Total & $130(100)$ & $17(100)$ & & \\
\hline "Number & & & \\
${ }^{*}$ No statistically significant difference in prevalence of the parasite among regions $(P>0.05)$
\end{tabular}

difference between the contamination rates and sampling site $(P>0.05)$. Table 2 shows the distribution of Toxocara species eggs in the soil samples of the specified sites regarding the soil areas examined. The highest rate of contamination was $32.29 \%$ in the Imam Khomeini area, compared to other areas investigated.

Toxocara eggs recovered from soil samples were developed into unembryonated and embryonated eggs. Overall, 17 Toxocara eggs were recovered, of which 10 (85.82\%) were fully embryonated.

\section{DISCUSSION}

Infectious diseases caused by soil-transmitted helminths (STHs) are important diseases of humans which affect about one-third of the world's population. From the public health perspective, soil examination is an effective substitute for faecal examination in epidemiological surveys of STH infection [10-16]. Earthworms may be play a significant role in transmitting the eggs in soils [17], as well as flies [18, 19]. Soil contaminated by eggs of the Toxocara species have been shown to be one of the main infection sources of toxocariasis [20]. The prevalence of Toxocara spp. eggs has been found in in soil samples in Spain (64-67\%) [20, 21], Brazil (62\%) [22], China (55.7-77.9\%) [23], Iraq (50.0\%) [24], and Poland $(4.5-50.0 \%)[25,26]$. In opposition to original thought, it has been shown that toxocariasis is highly prevalent in human life, and prevention of the transmission of the parasite to humans is necessary because of the different clinical (mild to severe) clinical complications.

The presented study is the first to identify and estimate soil contamination of Toxocara eggs in Ilam. However, studies have been conducted on the prevalence of human toxocariasis among different individuals, including children, pregnant women and diabetic patients in this region [27, 28]. The current study describes soil contamination with Toxocara spp. eggs from public places in 5 municipalities districts of the city of Ilam in Iran. The results of the study show that the contamination of soil samples with Toxocara spp. eggs was $13.08 \%$. The prevalence of Toxocara spp. ova in soil samples from public parks and other sites in Iran varied from $16.0 \%$ in Shiraz [29] up to $18.0 \%$ in Kermanshah [30], Isfahan 28.6\% [31], Abadan 29.2\% [32], Tehran 38.0\% [33], Ahvaz 38\% [34], and $63.3 \%$ in Khorram Abad [35].

The sampling period occurred in different weather conditions over a year. However, studies in the cities of Urmia, Tabriz, Ardabil, Amol and Mashhad in Iran showed a lower prevalence than the present study $(3.2-7.7 \%)[3,36]$. For development of Toxocara eggs in the soil, oxygen and humidity are required; however, the observed prevalence could also be significantly different if these environmental conditions are present. In a meta-analysis study on the prevalence of Toxocara species eggs in soil samples from 200-o 2016 in Iran, there was no significant correlation between Toxocara egg (16.0\%) and soil sample size [37]. As in the current study, soil contaminations by Toxocara spp eggs were found mostly in gardens [37]. In a similar study, the contamination rate of soil with Toxocara eggs in gardens has been reported in Mexico City [38].

\section{CONCLUSIONS}

The results of the present study show that the some public places in Ilam were contaminated with the faeces of animals and Toxocara eggs, indicating that control measures, as well as the education of the public, is needed for protection from zoonoses diseases.

\section{REFERENCES}

1. Baneth G, Thamsborg SM, Otranto D, Guillot J, Blaga R, Deplazes P, et al. Major parasitic zoonoses associated with dogs and cats in Europe. J ComP Pathol. 2016; 155: S54-S74.

2. Zibaei M, Bahadory S, Cardillo N, Khatami AR. Soil contamination with eggs of Toxocara species in public parks of Karaj, Iran. Int J Enteric Pathog. 2017; 5(2): 45-48.

3. Zibaei M, Sadjjadi SM, Jahadi-Hosseini SH. Toxocara cati larvae in the eye of a child: a case report. Asian Pac J Trop Biomed. 2014; 4(suppl): S53-S55.

4. Zibaei M, SM Sadjjadi. Trend of toxocariasis in Iran: a review on human and animal dimensions. Iran J Vet Res. 2017; 18(4): 233-242.

5. Zibaei M, Alemi M, Cardillo NM, Derafshi H, Miahipour A, Bahadory $S$, et al. Human toxocariasis seroprevalence among patients with uveitis in Alborz Province, Iran. Ann Agric Environ Med. 2019; 26(1): 154-158.

6. Sadjjadi SM, Khosravi M, Mehrabani D, Oryan A. Seroprevalence of Toxocara infection in school children in Shiraz, southern Iran. J Trop Pediatr. 2000; 46: 327-330.

7. Choi D, Lim JH, Choi DC, Paik SW, Kim SH, Huh S. Toxocariasis and ingestion of raw cow liver in patients with eosinophilia. Korean J Parasitol. 2008; 46: 139-143.

8. Mendonça LR, Figueiredo CA, Esquivel R, Fiaccone RL, Pontes-deCarvalho L, Cooper P, et al. Seroprevalence and risk factors for Toxocara infection in children from an urban large setting in Northeast Brazil. Acta Trop. 2013; 128: 90-95.

9. Zibaei M, Sadjjadi SM, Karamian M, Uga S, Oryan A, Jahadi-Hosseini SH. A comparative histopathology, serology and molecular study, on experimental ocular toxocariasis by Toxocara cati in Mongolian gerbils and Wistar rats. Biomed Res Int. 2013; 2013:109580.

10. Wolfe A, Wright I.Human toxocariasis and direct contact with dogs. Vet Rec. 2003; 152: 419-421.

11. Baldwin RA. Use of maximum entropy modeling in wildlife research. Entropy. 2009; 11: 854-866.

12. Hadi, MA. Isolation and identification of intestinal parasites from vegetables from different markets of Iraq. Bull Iraq Nat Hist Mus. 2011; 11(4): 17-25.

13. Hadi, M. Afkar. Isolation and identification of parasites from Lactuca sativa. J Al-Nahrain Univ Sci. 2011; 14(1): 134-141.

14. Robertson ID, Thompson R. Enteric parasitic zoonoses of domesticated dogs and cats. Microbes Infect. 2002; 4: 867-873.

15. King PML, Carlin EP. Zoonoses of people and their pets: a US perspective on significant pet-associated parasitic diseases. Trends Parasitol. 2010; 26: 153-154.

16. Keegan JD, Holland CV. A comparison of Toxocara canis embryonation under controlled conditions in soil and hair. J Helminthol. 2013; 87: 78-84.

17. Hadi MA, Al-Amery AMA. Isolation and identification of some parasites that transmitted by Earthworms. Al-Anbar J Vet Sci. 2010; 3(2): 68-72. 
18. Hadi MA. Isolation and identification of intestinal parasites and protozoa from flesh flies Sarcophaga africa in Baghdad. J Al-Nahrain Univ Sci. 2013; 16(3): 214-223.

19. Hadi MA. Isolation and identification of some intestinal parasites eggs, cysts and oocysts from two species of diptera: calliphoridae in Baghdad. Ibn Al-Haitham J Pure Appl Sci. 2013; 26(1): 64-74.

20. Giacometti A, Cirioni O, Fortuna M, Osimani P, Antonicelli L, Del Prete MS, et al. Environmental and serological evidence for the presence of toxocariasis in the urban area of Ancona, Italy. Eur J Epidemiol. 2000; 16: 1023-1026.

21. Ruiz de Ybáñez MR, Garijo MM, Alonso FD. Prevalence and viability of eggs of Toxocara spp. and Toxascaris leonina in public parks in eastern Spain. J Helminthol. 2001; 75(2): 169-173.

22. Gallina T, Silva MA, Castro LL, Wendt EW, Villela MM, Berne ME. Presence of eggs of Toxocara spp. and hookworms in a student environment in Rio Grande do Sul, Brazil. Rev Bras Parasitol Vet. 2011; 20(2): 176-177.

23. Gao X, Wang H, Li J, Qin H, Xiao J. Influence of land use and meteorological factors on the spatial distribution of Toxocara canis and Toxocara cati eggs in soil in urban areas. Vet Parasitol. 2017; 233: 80-85.

24. Nooraldeen K. Contamination of public squares and parks with parasites in Erbil city, Iraq. Ann Agric Environ Med. 2015; 22(3): 418-420.

25. Borecka A, Kłapeć T. Epidemiology of human toxocariasis in Poland - A review of cases 1978-2009. Ann Agric Environ Med. 2015; 22(1): 28-31.

26. Bojar H, Kłapeć T. Contamination of selected recreational areas in Lublin Province, Eastern Poland, by eggs of Toxocara spp., Ancylostoma spp. and Trichuris spp. Ann Agric Environ Med. 2018; 25(3): 460-463.

27. Raissi V, Sohrabi Z, Getso M, Raiesi O, Hafshejani SH, Shabandoust $\mathrm{H}$, et al. Risk factors and prevalence of toxocariasis in pregnant women and diabetic patients compared to healthy adults in Ilam province, western Iran. EXCLI J. 2018; 17: 983-988.

28. Khoshnood S, Pestehchian N, Hejazi SH, Rafiei A, Soleimani A, Ahmadi $\mathrm{M}$, et al. Toxocara seroprevalence and associated risk factors among Ilam children, west of Iran. Arch Pediatr Infect Dis. 2019; 7(1): e81349.
29. Choobineh M, Mikaeili F, Sadjjadi SM, Ebrahimi S, Iranmanesh S. Molecular characterization of Toxocara spp. eggs isolated from public parks and playgrounds in Shiraz, Iran. J Helminthol. 2019; 93(3): 306-312.

30. Ghashghaei O, Khedri J, Jahangiri-Nasr F, Hashemi SH, NourollahiFard SR. Contamination of soil samples of public parks with Toxocara spp. eggs in Kermanshah, Iran. J Fac Vet Med Istanbul Univ. 2016; 42 (1): $47-50$

31. Ghomashlooyan M, Falahati M, Mohaghegh MA, Jafari R, Mirzaei F, Kalani H, et al. Soil contamination with Toxocara spp. eggs in the public parks of Isfahan City, Central Iran. Asian Pac J Trop Dis. 2015; 5 (Suppl 1): S93-S95.

32. Maraghi S, Mazhab Jafari K, Sadjjadi SM, Latifi SM, Zibaei M. Study on the contamination of Abadan public parks soil with Toxocara spp. eggs. J Environ Health Sci Eng. 2014; 12: 86.

33. Tavalla M, Oormazdi H, Akhlaghi L, Razmjou E, Lakeh MM, Shojaee $\mathrm{S}$, et al. Prevalence of parasites in soil samples in Tehran public places. Afr J Biotechnol. 2012; 11(20): 4575-4578.

34. Khademvatan S, Abdizadeh R, Tavalla M. Molecular characterization of Toxocara spp. from soil of public areas in Ahvaz southwestern Iran. Acta Trop. 2014; 135: 50-54.

35. Zibaei M, Abdollahpour F, Birjandi M, Firoozeh F. Soil contamination with Toxocara spp. eggs in the public parks from three areas of Khorram Abad, Iran. Nepal Med Coll J. 2010; 12(2): 63-65.

36. Pezeshki A, Haniloo A, Alejafar A, Mohammadi-Ghalehbin B. Detection of Toxocara spp. eggs in the soil of public places in and around of Ardabil City, northwestern Iran. Iran J Parasitol. 2017; 12(1): 136-142.

37. Maleki B, Khorshidi A, Gorgipour M, Mirzapour A, Majidiani H, Foroutan M. Prevalence of Toxocara spp. eggs in soil of public areas in Iran: a systematic review and meta-analysis. Alexandria J Med. 2018; 54(2): 97-101.

38. Vásquez Tsuji O, Ruiz Hernández A, Martínez Barbabosa I, Merlín Marín PN, Tay Zavala J, Pérez Torres A. Soil contamination with Toxocara sp. eggs in public parks and home gardens from Mexico City. Bol Chil Parasitol. 1996; 51(3-4): 54-58. 